\title{
Giant Calvarial Ewing's Sarcoma: A Case Report
}

\author{
${ }^{1}$ Department of Neurosurgery, Okmeydani Education Hospital, \\ Istanbul, Turkey \\ J Neurol Surg Rep 2018;79:e79-e82.
}

Buse Sarigul $^{1} \quad$ Ece Uysal $^{1}$ Idris Avci ${ }^{1} \quad$ Halil Peker $^{1} \quad$ Suat Celik $^{1}$

\begin{abstract}
Address for correspondence Buse Sarigul, Department of Neurosurgery, Turkiye Cumhuriyeti Saglik Bakanligi Okmeydani Egitim ve Arastirma Hastanesi, Kaptan Paşa Mahallesi, Darülaceze Cad. No.: 27, 34384 Okmeydani, Şişli, Istanbul 34384, Turkey (e-mail: busesarigul90@hotmail.com).
\end{abstract}

Abstract
Keywords
- Ewing's sarcoma
- cranial metastases
- calvarial tumor
- bone tumor
- skull
- tumor

\section{Introduction}

Ewing's sarcoma (EWS) is the second most common primary bone tumor seen in children and adolescents, first being osteosarcoma. Peak incidence is in second decade of life ${ }^{1}$ with a slight male predominance. ${ }^{2}$ Skull lesions are seen in 6 to $9 \%$ of cases. The tumor tends to reside mostly on frontal and parietal bones. Squamous and petrous part of temporal bone, ethmoid bone, and mastoid bone are less frequently observed localizations of the tumor. Additionally, metastases to the central nervous system (CNS) develop in 10 to $37 \%$ of cases and spinal cord metastases are more common than cranial vault metastases. ${ }^{3}$ In the literature, majority of papers on calvarial EWS present cases with intracranial involvement; extracranial extension is reported in only eight cases. ${ }^{4}$

The case that we are presenting in this report is a 23-year-old patient with multiple infiltrations in femur, costal bones, and calvarium which had been diagnosed EWS radiologically and histopathologically. The calvarial metastasis had been very huge in size with dimensions of approximately $7.5 \times 7.5 \times 9.5 \mathrm{~cm}$.

\section{Case Report}

A 23-year-old male patient admitted to our hospital's Orthopedics and Traumatology department with left leg pain in

received

April 17, 2018

accepted

August 28, 2018 the 2009. Biopsy material had been taken from the femur of the patient and the pathology resulted as tumoral infiltration which composed of diffused small uniform cells with segmental minimal coagulative necrosis between tiny, bony trabecules; Ewing's Sarcoma Marker (EWS). The tumor had been found MIC-2 positive and Tdt negative.

After 3 doses of chemotherapy and radiotherapy, left femur had been excised to be implanted with platin material after 5 months. Eighteen months later a metastatic infiltration had been found in left groin and the patient took 24 doses of radiotherapy and remission had been observed. Two years later, the patient had received chemotherapy after left costal infiltration and operated by general surgery department in a different hospital. In F-18 FDG PET (Positron Emission Tomography) imaging that was taken 1 year later; a metastatic infiltration in left parietal region of calvaria had been reported. Patient complained of a bulge on the back of his left ear 1 year later this imaging. He declares that the bulging rapidly grew in size in 3 to 4 months. Moreover an operation had been planned after an infiltration had been discovered in right posterior costal bone. The patient receives high doses of strong analgesic drug therapy and he declares that the pain decreased after using transdermal fentanyl patches for the last year.

At the time of his admission to our department, his physical examination showed vital signs were stable. Glasgow Coma

\footnotetext{
(c) 2018 Georg Thieme Verlag KG Stuttgart . New York
}

License terms

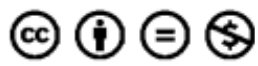


Scale (GCS) was 15. He had hearing loss in his left ear. Other cranial nerves were intact. In his motor and sensorial examination, there were no deficits in both upper and lower extremities. However, he had decreased range of motion of left lower extremity due to the operation he had 8 years ago.

In inspection, the calvarial infiltration could be observed posterior to auricula as an approximately $10 \times 10 \mathrm{~cm}$ bulge. The skin of the lesion on the mastoid process was telangiectatic and ecchymotic.

In radiologic imaging, the lesion was found to be in the left temporooccipital region with both extradural and intradural components. The tumor was hypointense in T1-weighted images and heterogeneously hypohyperintense in T2-weighted images. It invaded subdural space by eroding occipital bone. Moreover, there was effusion in left mastoid cells and indentation into left cerebellar hemisphere, left occipital, and parietal lobes (-Fig. 1). Additionally, on Magnetic Resonance Angiography (MRA), there was no blood flow in left transverse sinus and proximal internal vein.

Patient was operated in a park-bench position, the lesion site (left) stayed superiorly. Left arm was placed in a shoulder support and right arm was released freely supported by axillary pads. Mayfield head holder was pinned to the head with three pins; one on the left frontal region and two on the superficial temporal line. A modified $\mathbf{S}$-shaped incision was made on the infiltrated region (-Fig. 2). After the subcutaneous tissue was dissected, tumor was exposed and dissected with the help of monopolar cautery. The tumor was composed of two lobes and multilobulated with a surrounding capsule (-Fig. 3). It was a very firm solid mass with a texture of green and yellow colors and seemed highly vascularized (-Fig. 4). After the tumor was dissected from surrounding soft tissue, a craniotomy was applied to the periphery of the tumor involving bone with a tumor free margin of approximately $1 \mathrm{~cm}$. The bone was cautiously lifted and highly vascularized epidural component of the tumor was exposed. Hemostasis was achieved via bipolar cautery for the vascular supply of the tumor. After hemostasis, excision of the tumor extension into the mastoid sinus air cells was achieved by otolaryngologists.

The intradural component of the tumor was not resected since there was massive bleeding after removal of the bone.

After craniectomy was performed, we did not perform cranioplasty. Therefore the patient could receive radiotherapy to the calvarium after recuperation period.

\section{Discussion}

EWS is a tumor mostly seen in in children and young adults with a peak incidence between ages 5 to 13 years. ${ }^{5}$ It is a highly malignant bone tumor ${ }^{5}$ that is the second most common primary bone cancer in childhood. Annual incidence of EWS in United State was 2.93 per 1 million between the years 1973 and $2004 .^{4}$

It usually occurs as a solitary lesion in long bones, ribs, and flat bones. ${ }^{6}$ Skull infiltration is rare with an incidence of 1 to $2 \%$ of EWS. ${ }^{4}$ EWS mostly infiltrates frontal, parietal, temporal bones and skull base with the most common involvement being parieto-occipital region. ${ }^{5}$ Squamous and petrous part of temporal, ethmoid, and mastoid bone are less frequently observed localizations of the tumor. ${ }^{3}$ EWS typically grows extradurally and often reaches a very large size before dural invasion, or clinical detection, or both. ${ }^{7}$ Although intracranial involvement was seen in the majority of calvarial EWSs;

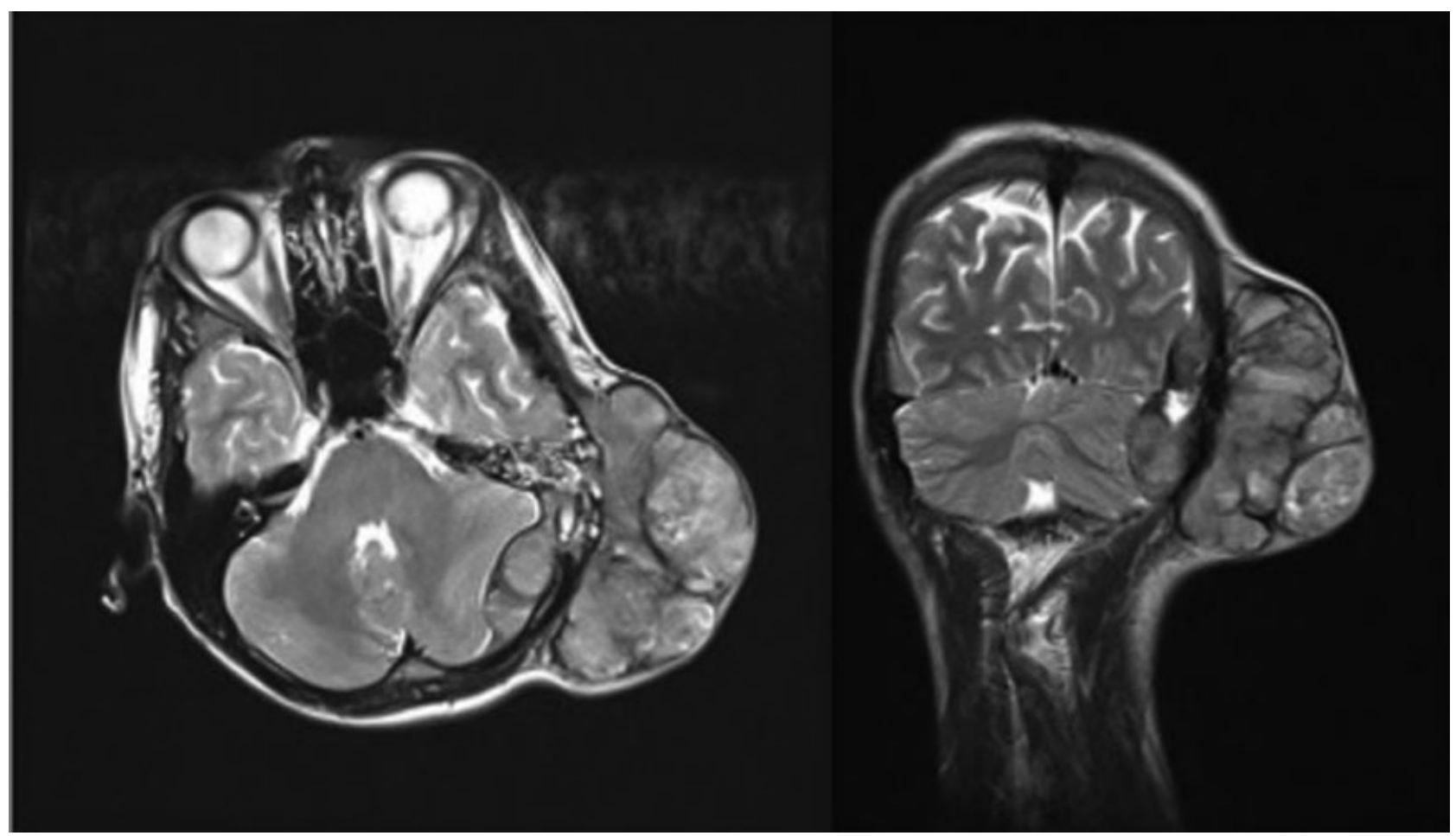

Fig. 1 Preoperative T2-weighted axial and coronal imaging of the tumor. 


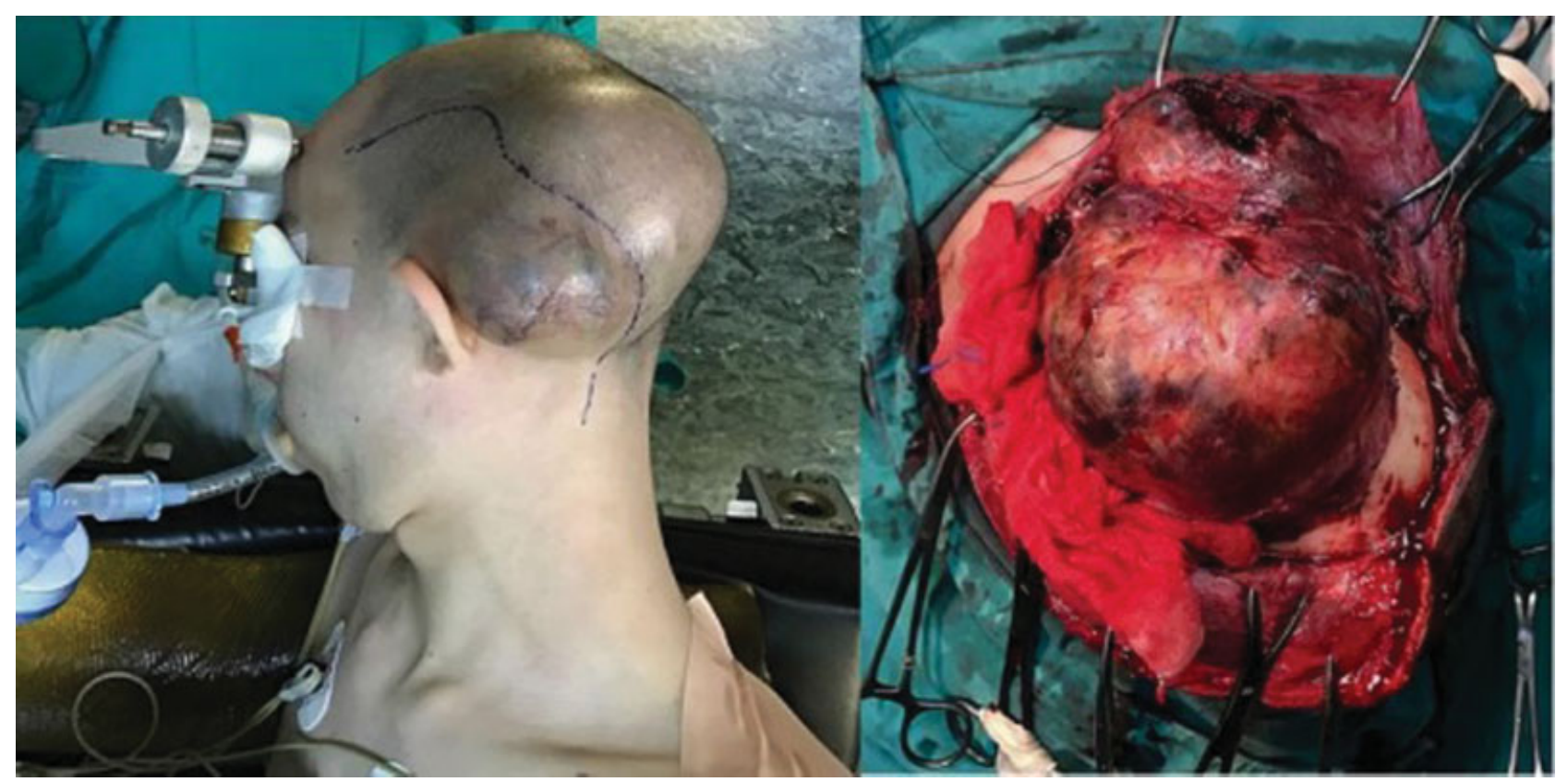

Fig. 2 (A) Patient positioned in a park-bench position with the left side of the head staying upwards. The modified S-shaped skin incision is shown. (B) Intraoperative image after the tumor is dissected from adjacent healthy tissue.

extracranial extension was observed in only eight cases in the literature. $^{4}$

The most common symptoms associated with calvarial EWS are caused by increased intracranial pressure. Local headaches, bulging, and swelling on the calvarium, papilledema, and vomiting are the most common reported signs. ${ }^{8}$

On plain X-ray imaging, calvarial EWS has a lytic appearance with mottling and erosion. ${ }^{5}$ Computed tomography (CT) and magnetic resonance imaging (MRI) imaging may show the extent of tumor into the dura and brain parenchyma. ${ }^{5}$ On MRI, the tumor is hypoisointense on T1-weighted images and isohyperintense on T2-weighted slices. ${ }^{5}$ Tumor has necrotic foci, hemorrhage, and contain multiple cysts which can also be observed on MRI imaging. On F-18 FDG PET/CT, the tumor seems strongly labeled. ${ }^{4}$ Peritumoral edema may be an indicator of high malignancy ${ }^{9}$. "Dural tail sign" can be seen with EWS and considered as a benign response but mostly it is an atypical tail because of the aggressive nature of the tumor. ${ }^{9}$

Ewing sarcoma is a tumor that is categorized in small round cell tumors. The typical histological signs of EWS are round cells with a solid strata, protruding nuclei, no rosette

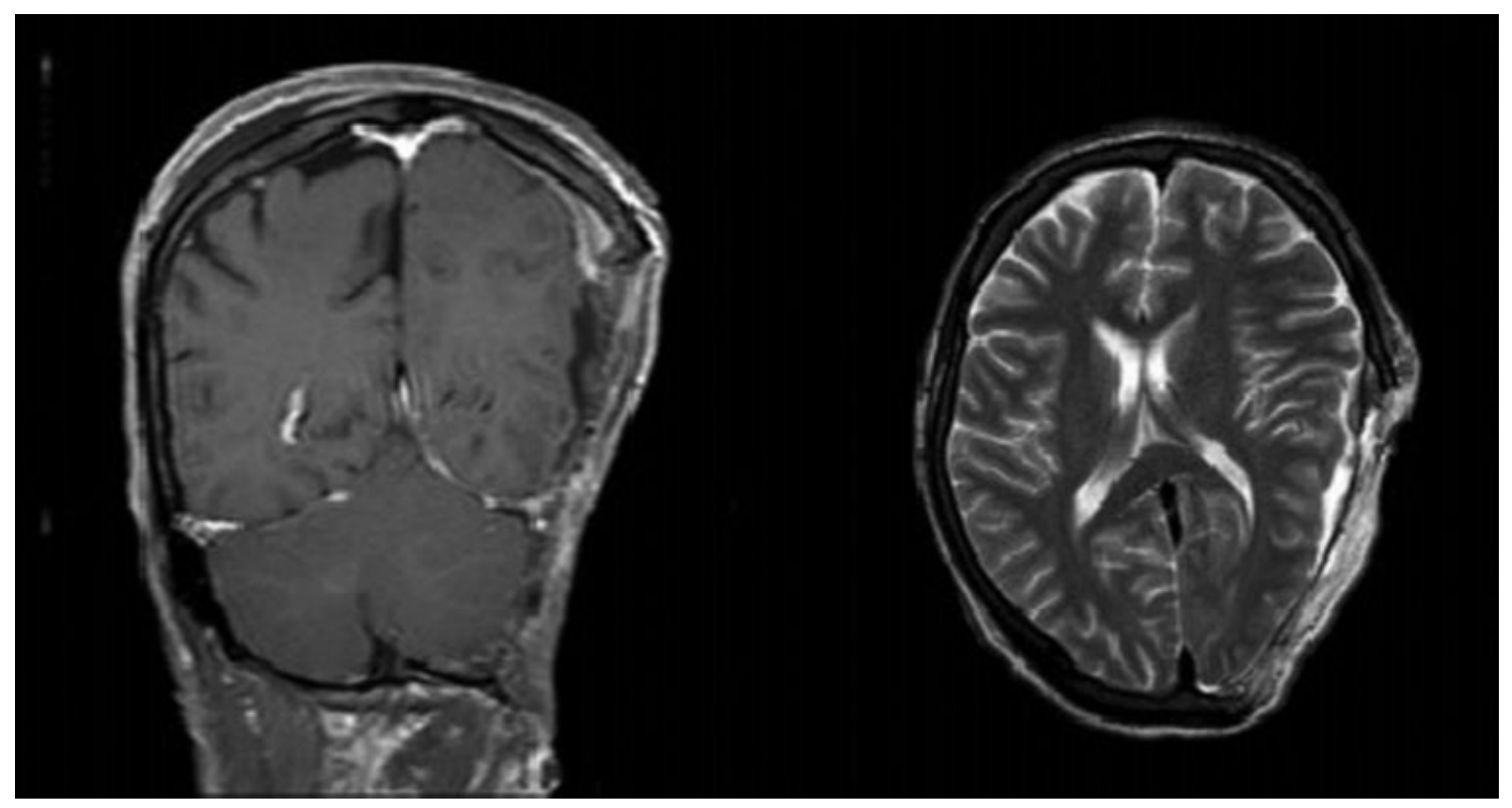

Fig. 3 Postoperative magnetic resonance imaging with contrast 


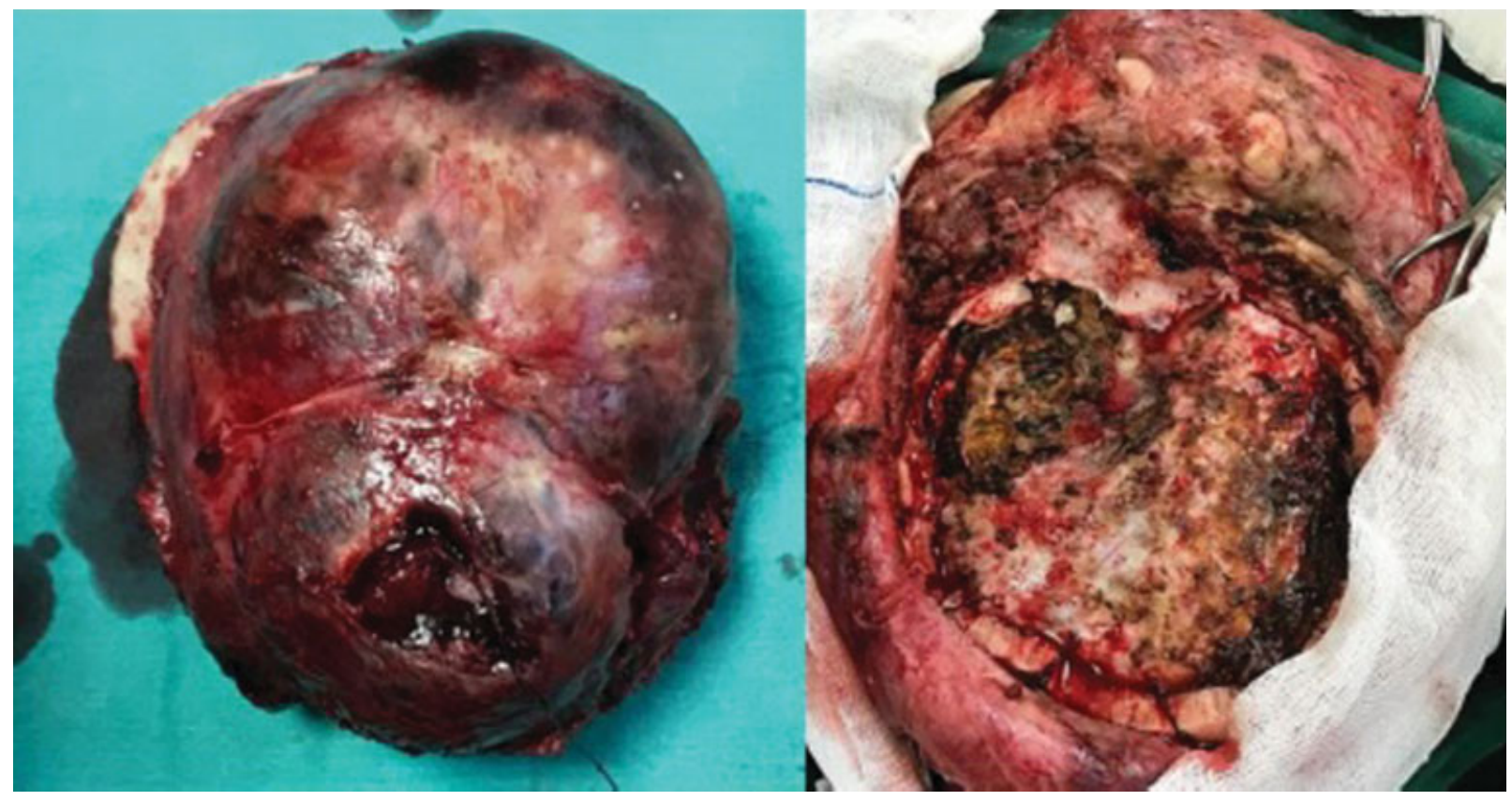

Fig. 4 (A) Excised tumor with the calvarium that has been removed. (B) Dura can be seen after the removal of the tumor.

formation, mitosis, and preence of bone structures. ${ }^{8}$ Ninetyfive percent of the cases involve $t(11 ; 22)$ (q24;q12) translocation of chromosome $22 .{ }^{10}$ CD99 and FLI- 1 are useful in diagnosis of EWS; however, they are not specific since CD99 expression may also be seen in rhabdomyosarcomas, lymphoblastic lymphomas/leukemias, synovial sarcomas, and neuroendocrine tumors. Also, FLI-1 positivity may be observed in vascular tumors and lymphoblastic lymphoma. ${ }^{11} \mathrm{~A}$ final diagnosis is made with a combination of histological, immunohistochemical, and molecular tests. ${ }^{11}$

Treatment of cranial EWS involves surgical resection and/or radiotherapy. If the lesion is resectable, surgery is the preferred choice. However, as it is not possible to have a total resection of this tumor at a microscopic level, localized radiotherapy at a dose of 40 to $50 \mathrm{~Gy}$ is recommended postoperatively. ${ }^{5}$

Metastases are seen less frequently and prognosis of calvarial EWS is better than those seen in other areas. ${ }^{5}$ When a combination treatment of total excision, radiation, and standard chemotherapy regimen which involves application of vincristine, cyclophosphamide, doxorubicin/ifosfamide, and etoposide; survival in 5-year follow-up ranges from 39 to $65 \% .^{5}$

\section{References}

1 Choi EY, Gardner JM, Lucas DR, McHugh JB, Patel RM. Ewing sarcoma. Semin Diagn Pathol 2014;31(01):39-47
2 Balamuth NJ, Womer RB. Ewing's sarcoma. Lancet Oncol 2010;11 (02):184-192

3 Cherekaev VA, Kushel' IuV, Shkarubo AN, et al. [Primary and metastatic Ewing sarcoma of the skull base - case reports and comparative analysis]. Vopr Neirokhir 2013;77(01):30-36, discussion 36

4 Kawano H, Nitta N, Ishida M, Fukami T, Nozaki K. Primary pericranial Ewing's sarcoma on the temporal bone: a case report. Surg Neurol Int 2016;7(Suppl, 15):S444-S448

5 Sujan MU, Rao MR, Kisan R, et al. Influence of hydrotherapy on clinical and cardiac autonomic function in migraine patients. J Neurosci Rural Pract 2016;7(01):109-113

6 Salunke P, Sharma M, Gupta K. Ewing sarcoma of the occipital bone in an elderly patient. World Neurosurg 2014;81(02):e10-e12

7 Winn HR. Youmans \& Winn Neurological Surgery. 7th ed. New York, NY: Elsevier;2016:1322-1343

8 Pfeiffer J, Boedeker CC, Ridder GJ. Primary Ewing sarcoma of the petrous temporal bone: an exceptional cause of facial palsy and deafness in a nursling. Head Neck 2006;28(10):955-959

9 Jing Z, Wen-Yi L, Jian-Li L, Jun-Lin Z, Chi D. The imaging features of meningeal Ewing sarcoma/peripheral primitive neuroectodermal tumours (pPNETs). Br J Radiol 2014;87(1041);20130631

10 Güzel A, Tatli M, Er U, Yilmaz F, Bavbek M. Multifocal Ewing's sarcoma of the brain, calvarium, leptomeninges, spine and other bones in a child. J Clin Neurosci 2008;15(07):813-817

11 Mardekian SK, Gandhe A, Miettinen M, Pack S, Curtis MT, Abdullaev Z. Two cases of spinal, extraosseous, intradural Ewing's sarcoma/peripheral neuroectodermal tumor: radiologic, pathologic, and molecular analysis. J Clin Imaging Sci 2014;4:6 